\title{
QUALITY STANDARDS AND TARGET OUTPUTS BASED ON BENCHMARKING STUDIES IMPROVED BY A PROPOSED PROSPECTIVE BALANCED-SCORECARD MODEL FOR THE MONTRÉAL PUBLIC LIBRARIES SYSTEM
}

\author{
Pierre Meunier, Montreal Public Libraries System \\ with the collaboration of Susan Nguyen, Gina Pinet, Nancy Asselin
}

\begin{abstract}
According to the ideas generated by the Montréal Summit in 2002, it was inevitable that the Public Libraries System would have to be consolidated following the merger of 28 municipalities on the Island of Montréal. Public libraries are considered a 'proximity service' and come under the responsibility of each borough. The situation was analyzed (the diagnosis) and a 10-year term Consolidation Plan (2005-2014) was developed. The Consolidation Plan includes strategic axes and specific objectives. Thresholds defined by minimal standards of service and estimated by clear indicators of performance in each of the fields of normalization are in place to ensure that the specific objectives are met. The Consolidation Plan also provides spaced target outputs during the 10-year term. The financial investment to support this Consolidation Plan is estimated at more than CDN\$230 million.
\end{abstract}

A Prospective Balanced-Scorecard Model is proposed as a progressive evaluation method of the Consolidation Plan settlement process, which is based on the introduction of new minimal standards of service and performance measures. In general, performance measures are based on ISO standard 11620, but some original standards and performance measures will be adapted to the specific needs of a public library system in an urban region including the large disparities as were determined in Montréal. Selected statistical indicators, standards and performance measures projected for balanced scorecard model are presented.

The goal of this multi-level Balanced Scorecard is to effectively describe the performance of the Public Libraries System and, more specifically, centralized units - strategic and tactic levels (Planning and Development, Programs and Services to Boroughs, Cataloguing, Classification and Processing Departments) and Decentralized Public Services - Operational Level (branch libraries under the responsibility of boroughs) in order to apply new strategies and orientations of services as determined by the new Framework. In developing the Consolidation Plan, it was noted that its success would depend on the prioritization of determining the main quality standards and target outputs, which will be estimated and projected by simulations, based on correlation analysis, and benchmark studies with Canadian Urban Public Libraries Systems serving more than 500, 000 inhabitants. Finally, the Prospective Balanced-Scorecard Model facilitates the evaluation of interdependent outputs and dimensions of library activities 


\section{PURPOSE OF THIS PAPER}

Before presenting the Proposed Balanced Scorecard Model for Montreal Public Libraries System and the benchmarking process, it is important to point out some aspects of the municipal administration in Quebec. First, the public libraries are under the responsibility of municipal government. Besides, a great majority of the 105 public libraries located in the largest municipalities (serving 5,000 or more residents), are managed by their municipal administration by virtue of their municipality's charter. The provincial Ministry of Culture (Ministère de la Culture, des communications et de la condition feminine) sets up different grant programs to support the development of library networks.

In 2002. the provincial government of Quebec decided to proceed to the amalgamation of large municipalities. By decreeing and defining the specific legislative framework in the municipal merger process, the former cities (as Montreal) and towns were obliged to set out and provide minimum service standards. These obligations are specified by classes 143 until 146 of the new City Charter of Montreal. The municipality must fix the level of services in each of the boroughs to assure service offerings in municipal libraries. Furthermore, by virtue of this legislation, the application of standards may not in any way compromise the autonomy of local library service management by the direction of boroughs. Also, it is important to mention the proposed standards may not in any time concern the other independent municipalities located on Montreal Island.

This legislation confirms the managerial autonomy of the boroughs as it relates to libraries. Also, the borough budget must be established by respecting these minimum service standards. The objective of establishing such standards is mainly to secure equality in documentary services for the citizens of the 19 boroughs of new city of Montreal by protecting a minimum threshold defined by norms. For this purpose balance in the endowments process will be a function of disparities based on minimal standards and the service levels will be defined by the Consolidation Plan. The quality standards must guarantee the minimum service levels in each borough. The Direction of the Montreal public libraries uses this opportunity to propose new standards of minimum services (quality standards) and to introduce performance measures to the new library system. For this reason, the situation was analyzed (the diagnosis) to evaluate the disparities in socio-demographic factors, to determine the deficiencies in resources and to estimate the imbalance in the service offer. Finally a 10-year term Consolidation Plan (2005-2014), based on new minimal standards of quality, was proposed to upgrade the level and variety of services.

Now, a Prospective Balanced Scorecard Model is proposed as a progressive evaluation method of the Consolidation Plan settlement process, which is based on the introduction of new minimal standards of service and performance measures.

This paper provides a brief presentation of the diagnosis of disparities and imbalance of resources and of the Consolidation Plan. In the second part, the Bal- 
anced Scorecard Model is described in terms of a conceptualization approach and of its contents (management concerns (or objectives), selected quality standards and target outputs, performance indicators). Also, the proposed Scorecard model includes related measures and considers the interdependence of marketing dimensions. Finally, the evaluation of the contributions of branches and boroughs, by specific investments and initiatives to strategies related to the Consolidation Plan, will be represented by the Operational Balanced Scorecard, utilising cascading and drilling processes. Some original and innovative standards are proposed to be inserted in the Balanced Scorecard to support the Consolidation Plan and to take count of disparities between boroughs.

The goal of this multi-level Balanced Scorecard is to describe effectively the performance of the Public Libraries System and, more specifically, centralized units - strategic and tactic levels (Planning and Development, Programs and Services to Boroughs, Cataloguing, Classification and Processing Departments) and Decentralized Public Services - Operational Level (branch libraries under the responsibility of boroughs) in order to apply new strategies and orientations of services as determined by the new Framework. In developing the Consolidation Plan, it was noted that its success would depend on the prioritization of determining the main quality standards and target outputs, which will be estimated and projected by simulations, based on correlation analysis, and benchmark studies with Canadian Urban Public Libraries Systems serving more than 500,000 inhabitants. Finally, the Prospective Balanced Scorecard Model facilitates the evaluation of interdependent outputs and dimensions of library activities

\section{DESCRIPTION OF THE NEW PUBLIC LIBRARY SYSTEM OF MONTREAL}

Statistics for 2005 (the first year of the next ten-year term of the Consolidation Plan), 4 years after the merger of municipalities on the Island of Montreal, show that the new library system with 44 libraries located in 19 boroughs welcomes a little under 6 million visitors $(5,110,000$ entries) and makes about 8.3 million loans to 549,162 active library users. In addition, this network, which has more than 600 employees (618.3 FTE) preserves, manages, develops and promotes a stock of several million documents. A Bookmobile as well as mail and drop-off services for the elderly add to this service offering. There are more than 3.2 million printed monographs. (that is 2.06 books per inhabitants). The whole represents an investment of about CDN\$66.5 million a year.

As for the population of the new municipality of Montreal, it now totals $1,562,660$ inhabitants. The library system succeeded in reaching $35.1 \%$ of the total population. In certain boroughs, more than two-thirds of the residents were and are active members. 


\section{ASSESSMENT AND CONSOLIDATION PLAN}

Following the merger of the former suburbs and city of Montreal, located on Montreal Island, the government of Quebec and the City of Montreal realized the necessity of analysing the state of the library system, to determine priority improvements and plan its consolidation. The Service of Cultural Development of the City of Montreal and the Ministry of Culture and Communications of Quebec shared the responsibility of carrying out this diagnosis. It aimed at profiling the situation of the libraries of the Island as a whole, both internally (resources) and externally (utilisation figures) by examining the following sectors:

- human and documentary resources and buildings;

- services to the library users;

- services to libraries;

- clients or library users;

- new technologies;

- performance of services;

- service area.

A preliminary report was submitted to the Ministry of Culture and Communications of Quebec in August 2003. An improved version including a more detailed description of the strengths and weaknesses of some components of the library system and a comparative analysis was completed and submitted. This analysis dress the principal weaknesses and disparities of 44 service points in 19 boroughs relatively to Annual opening hours, Staff, Document resources and Space Area.

The results of our Assessment for 2002's figures were presented in details in the first part of our presentation at 2005's IFLA Satellite Conference held at Bergen (Norway) An updated version, including figures for 2004 has been produced. These documents are available on request.

In comparison with library systems of Canadian cities serving 500,000 residents and more, Montreal Public libraries present these imbalances:

- human resources

o shortfall of 132.5 librarians

o shortfall of 518.9 employees

- collections

o shortfall of 1,628,640 books

- space

o shortfall of $31,903 \mathrm{~m} 2$

- opening hours

o shortfall of 25,265 opening hours

Considering that there was a gap between supply and demand (that is the deficiency of the resources required by virtue of expected needs and of levels of use of the 
services and the documentary resources anticipated by comparison with tendencies followed by large Canadian public library systems with superior performance), and disparities in the resources and socio-demographic characteristics among the boroughs of the new city, new standards favouring the diversification of the levels of documentary services must be conceived. The project of Montreal public libraries illustrates the importance of defining minimum standards and determining performance measures according to the mission and specific objectives of the organization.

To redefine the new standards that must be recommended for Montreal, it seemed relevant to opt for a transverse approach inspired by management through goals. Therefore, according to the specific objectives retained, the identification of normative indicators (minimum service standards) and of performance indicators, to measure the degree of deviation from the standards, seems more coherent and more justifiable.

A strategic planning sub-committee was put in charge of developing a strategic plan and submitting it to the minimum standards committee. This plan contains five strategic goals or axes and 17 specific objectives.

To redefine the new standards that had to be recommended for Montreal, it seemed relevant to opt for a transverse approach inspired by management through goals. Therefore, according to the specific objectives retained, the identification of normative indicators (minimum service standards) and of performance indicators, to measure the degree of infringement of the standards, seems more coherent and more justifiable.

A strategic planning sub-committee was put in charge of developing a strategic plan and submitting it to the minimum standards committee. This plan contains five strategic goals or axes and 17 specific objectives. These strategic goals are:

- Ensure Montreal's population has access to high-quality service

- Increase readership and library visits among people under 17 years of age

- Strengthen library use as a tool for integration and social development

- Reinforce the role of libraries as a way of life

- Promote Montréal as a city of reading and knowledge

This Consolidation Plan provides a 10-year term (2005-2014) to upgrade the resources and the number of service points.

We can consider during the first two years the starti has been very slow but the next steps will be more determinant. In 2005, we began the harmonization of 8 distinctive integrated library systems by replacement with the new system Millenum. In 2006, according to the deficit of opening hours in $68 \%$ of the 19 boroughs, we increased the minimum opening hours to 47 and purchased multimedia (DVD) documents for the service points of former city of Montreal. In 2007, we will upgrade the minimum opening hours to 53 during the year and to 47 in Summer. 
Also, the plan provides to increase substantially staffing levels (librarians: $110 \%$; other employees: $57,4 \%$ ) to improve quality of service, reader advisory and reading programs in target boroughs. Finally, it will provide universal loan and returns.

The same Consolidation Plan includes investments:

- to improve $39.5 \%$ of the depth of book collection in $80 \%$ of the boroughs (investment in 2006 equivalent to only $1.7 \%$ of projected costs for multimedia materials);

- to create start-up collections for new libraries;

- to develop thematic collections (multiculturalism, francisation and return to school),

Finally, some important funds will serve to make more space available - an increase of $54 \%$ in more than $84 \%$ of the boroughs (more than a dozen real estate projects: additions, up-date to standards, relocations and expansions)

Considering the amplitude of required investments (an average of CDN\$200 million) to reduce and eliminate the gap with large and urban Canadian public libraries, probably we will be obliged to include an additional three-year term to the original plan (until 2017). It is really a sprint as a race against the clock comparatively to the intensive and continuous development of other Canadian large public libraries.

But, with the innovation as outreach programmes, liaison agents with the population of boroughs, mobile libraries and new approaches based on Public libraries without wall, we are sure our investments will have substantial impacts on the library uses and the output.

Important increase of all indicators of library uses: during next ten years we anticipate doubling the circulation $(9,287,000$ additional loans) and the number of visitors ( 5 million more visitors) and increasing the market penetration rate from $10 \%$ to $15 \%$.

Finally, the assessment completed in 2005 is the first step of our transverse approach as an integrated planning system. The new orientations and positions concerning new roles and objectives for Montreal public libraries (included in the Consolidation Plan) will be based on the progressive standard achievement of efficiency and effectiveness. All the parts of this transversal approach will cover the entire documentation chain and all facets of library services and resources.

\section{BALANCED SCORECARD CONCEPTUALIZATION}

A Prospective Balanced Scorecard Model is proposed as a progressive evaluation method of the Consolidation Plan settlement process, which is based on the introduction of new minimal standards of service and performance measures for 10 measurable management concerns according to these 5 marketing dimensions: 
- clientele

- process

- outreach and development (or scope of activities and development)

- infrastructure

- and financial plan.

The goal of this multi-level Balanced Scorecard is to describe effectively the performance of the Public Libraries System in terms of effectiveness, efficiency, consistency, relevance, impact and outcomes in relation to targets: standards - minimum service levels and expected output and, more specifically for

- Centralized units (strategic and tactic levels):

o Planning and Development

o Programs and Services to Boroughs

o Cataloguing, Classification and Processing

and for

- Decentralized Public Services (Operational Level):

o branch libraries under the responsibility of boroughs

in order to apply new strategies and orientations of services by relevant and appropriate initiatives to deliver optimal services.

In developing the Consolidation Plan, it was noted that its success would depend on the prioritization of determining the main quality standards and target outputs, which will be estimated and projected by simulations (or projections) and benchmark studies. Finally, the Prospective Balanced Scorecard Model will facilitate the evaluation of interdependent outputs and dimensions of library activities. (Figure 1)

In general, performance measures are based on ISO standard 11620, but some original standards and performance measures will be adapted to the specific needs of a public library system in an urban region, including the large disparities as have been determined at Montréal.

Some difficulties were expected with application of Kaplan's Balanced Scorecard conceptualization approach based on the selection of limited objectives, as aim and objectives related to general mission of an enterprise. The success of the Consolidation Plan settlement process of the new Montréal Public Libraries needs to be evaluated more by performance measures related to management concerns provided by the 10-year term than by any measures related to the realization of specific objectives.

Specialists at the business school affiliated with the Université de Montréal recommended us an appropriate solution. They proposed these three approaches:

- splitting the mission into three strategic axes,

- dividing measurable management concerns into five marketing dimensions

- evaluating the performance of the five marketing dimensions (Figure 2):

o clientele,

o processes, 


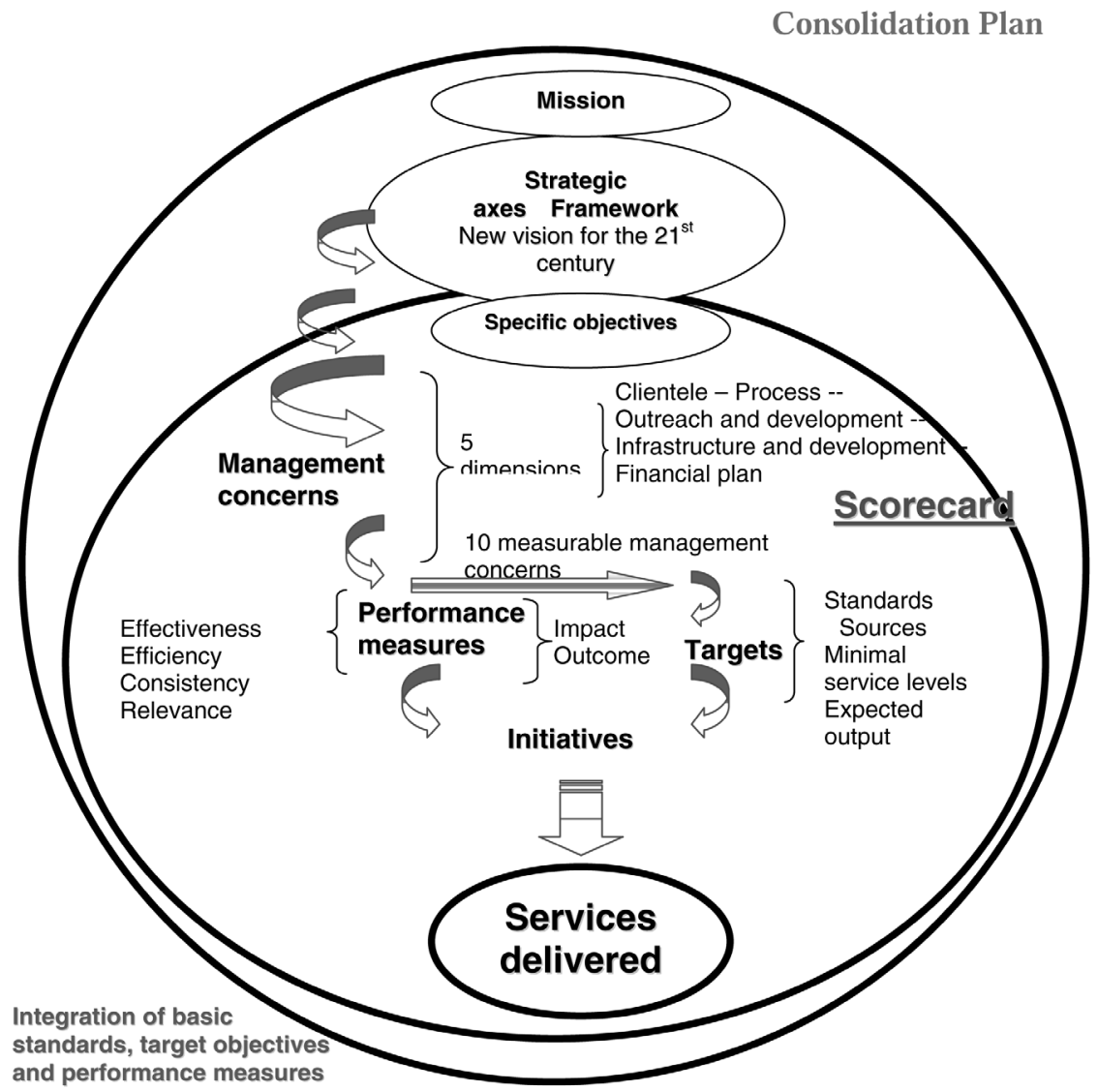

Figure 1: Consolidation Plan

o scope of activities and development = outreach and development : including territory covered, mediation and development of outreach as libraries without walls and promoting programs,

o infrastructure: documentary resources, NTIC and space areas

o and, finally, financial support.

The selection of specific objectives and/or management concerns related to strategic decisions in comparisons to the operational follow-up process were classified and defined by a cascading process in two distinctive and related Balanced Scorecards:

- 'Strategic': highest level - strategic and tactic levels

- 'Operational': intermediary and first levels - operational levels. 


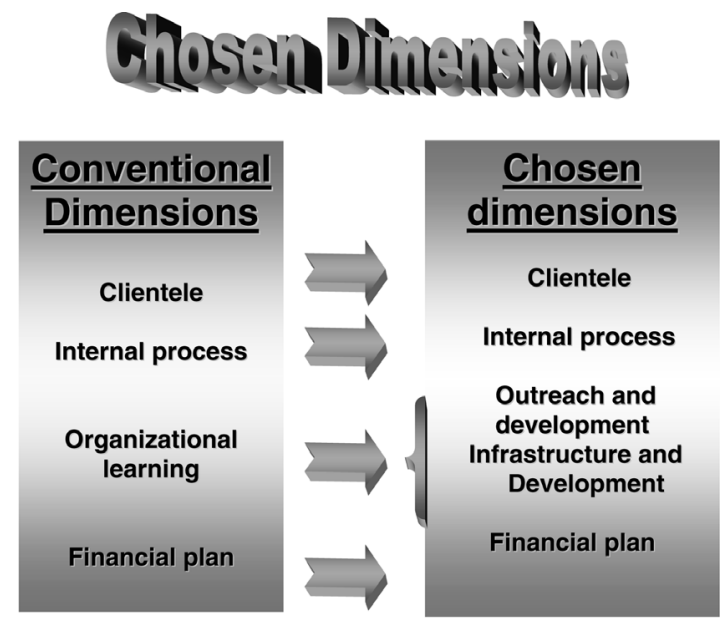

Figure 2: Marketing dimensions

By our transverse approach, for each marketing dimensions, the specific objectives of the Consolidation Plan in terms of measurable management concerns will be evaluated in terms of performance indicators according to expected outputs or to minimum required resources (standards). These direct relations between the Consolidation Plan with standardization process and balanced scorecard in terms of performance measures are illustrated in the following figure. (Figure 3)

According to five marketing dimensions and these ten measurable management concerns, the Consolidation Plan can be redefined by the first three strategic axes related to the general mission: to reinforce the role of libraries as a way of life to support the development of reading and knowledge.

\section{A NEW FRAMEWORK: MONTREAL PUBLIC LIBRARIES SYSTEM AT THE CROSSROADS OF A NEW VISION OF THE $21^{\text {ST }}$-CENTURY WORLD}

In the age of new technologies the public libraries of Montreal must develop expertise as information centers and an essential source of development of knowledge for the community. The libraries will be the principal site of knowledge sharing and training by offering new services outside the wall as access at a distance to collections and electronic documents, virtual and electronic reference and access to outside resources. Also, by the hybrid model of libraries, the challenge will be to preserve the diversity and variety of collections of traditional libraries and to include in the new orientations a profile of services more focused on the age of information and the development of knowledge. 


\section{Consolidation Plan, Scorecard and Standardization}
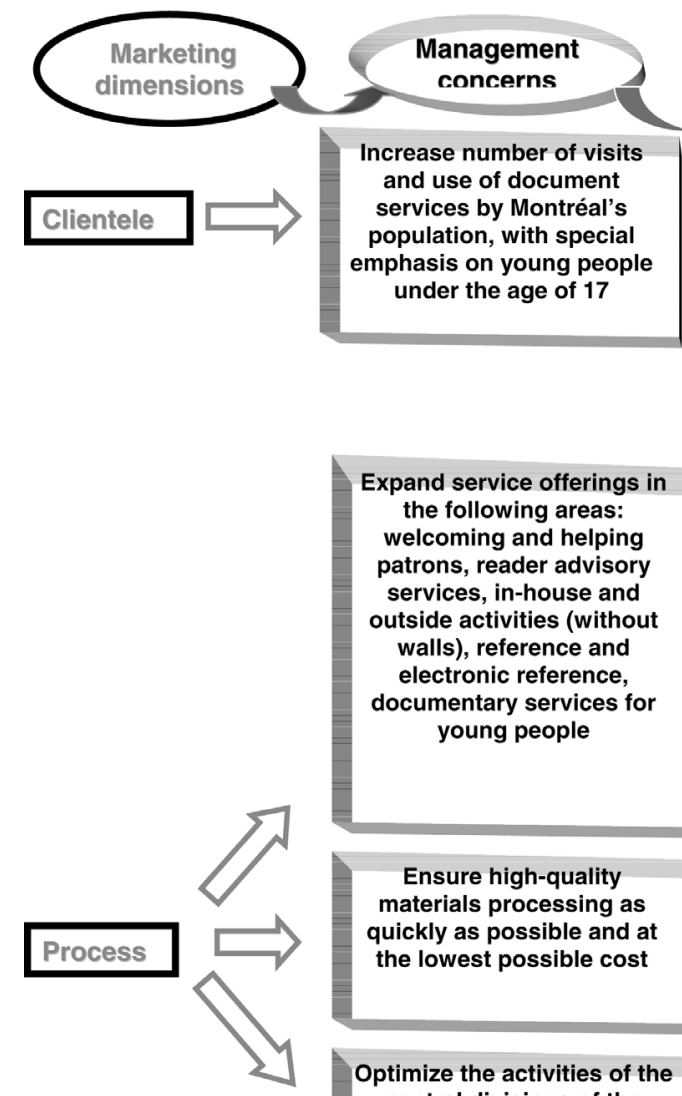

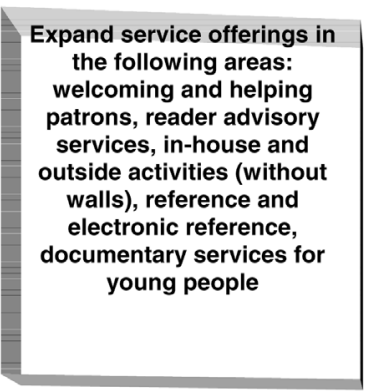

Ensure high-quality materials processing as quickly as possible and at the lowest possible cost

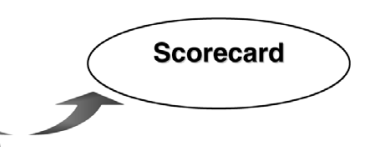

1.1 Loans per capita

1.2 Total loans per capita by segment

1.3 Visits per capita

1.4 Penetration rate
Optimize the activities of the central divisions of the Montréal libraries System with regard to the Consolidation Plan
2.1 Human resources

2.2 Reference questions per professional

2.3 Liaison agents per borough
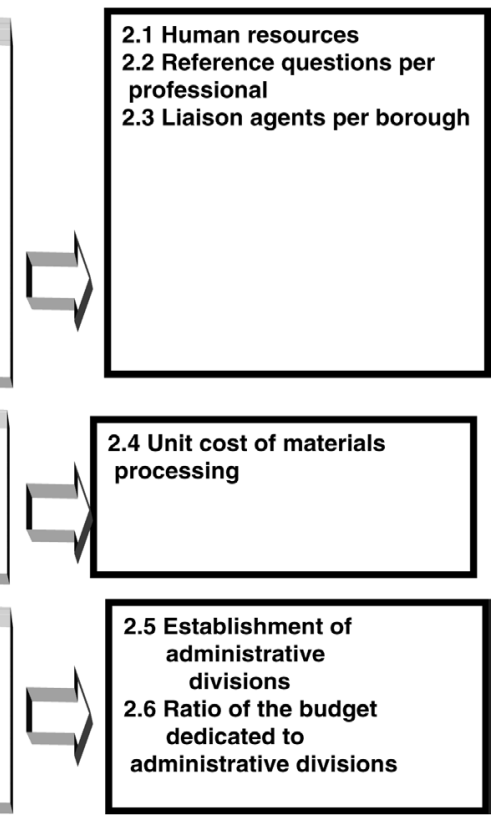

Figure 3a: Consolidation Plan and Balanced Scorecard

The new Framework by a strategic plan provides new orientations including the settlement and realisation of the Consolidation Plan and a development plan of new services based on a new integrated standardization program and performance evaluation indicators process. 


\section{Consolidation Plan, Scorecard and Standardization}

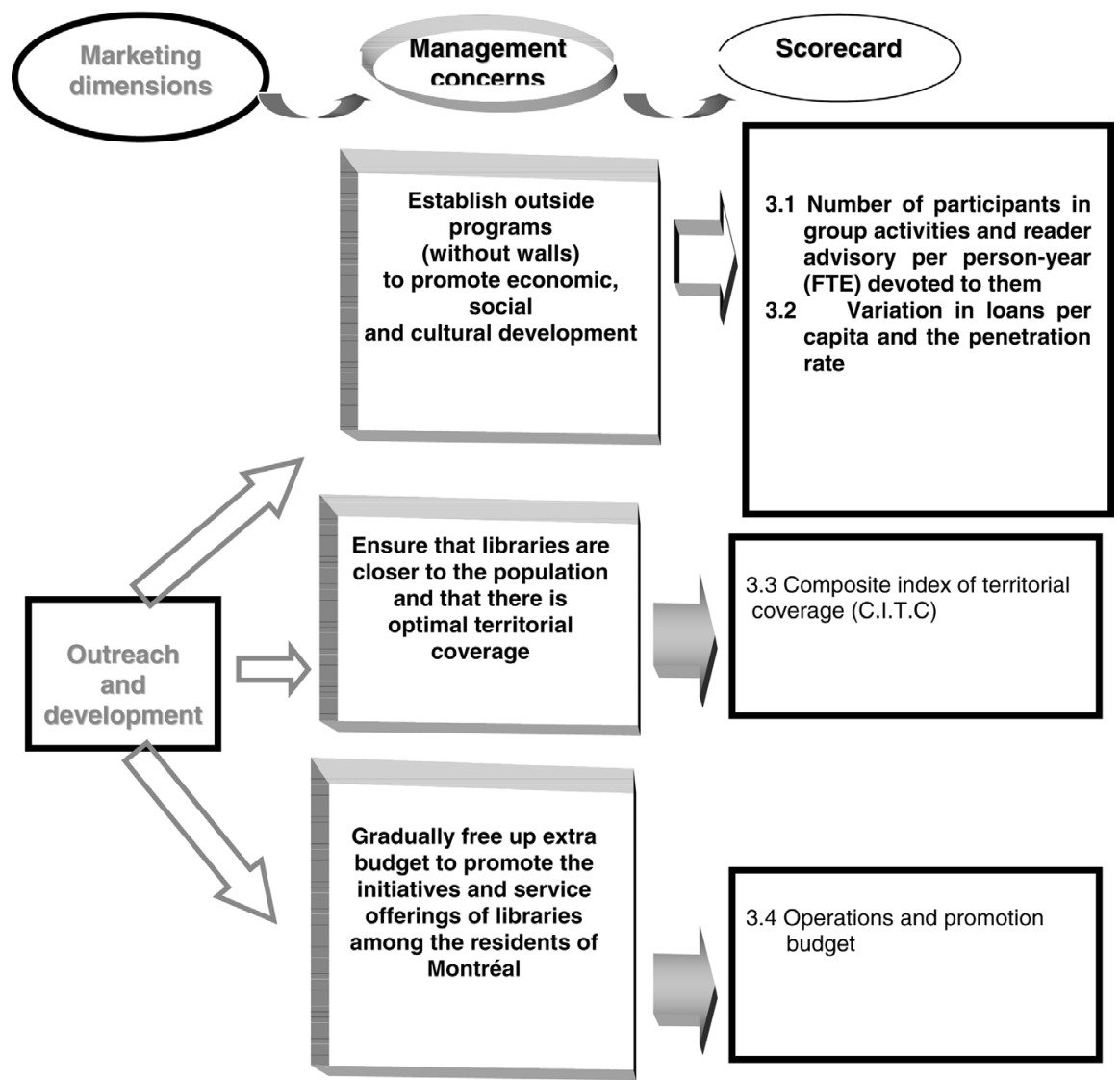

Figure 3b: Consolidation Plan and Balanced Scorecard

This new vision for $21^{\text {st }}$-century world means 7 strategic initiatives:

- New outreach and mediation programs (supporting more social inclusion and knowledge development);

- Multi-level branches as satellite service points, resources libraries and proximity services;

- New partnership with other library systems; 


\section{Consolidation Plan, Scoreboard and Standardization}
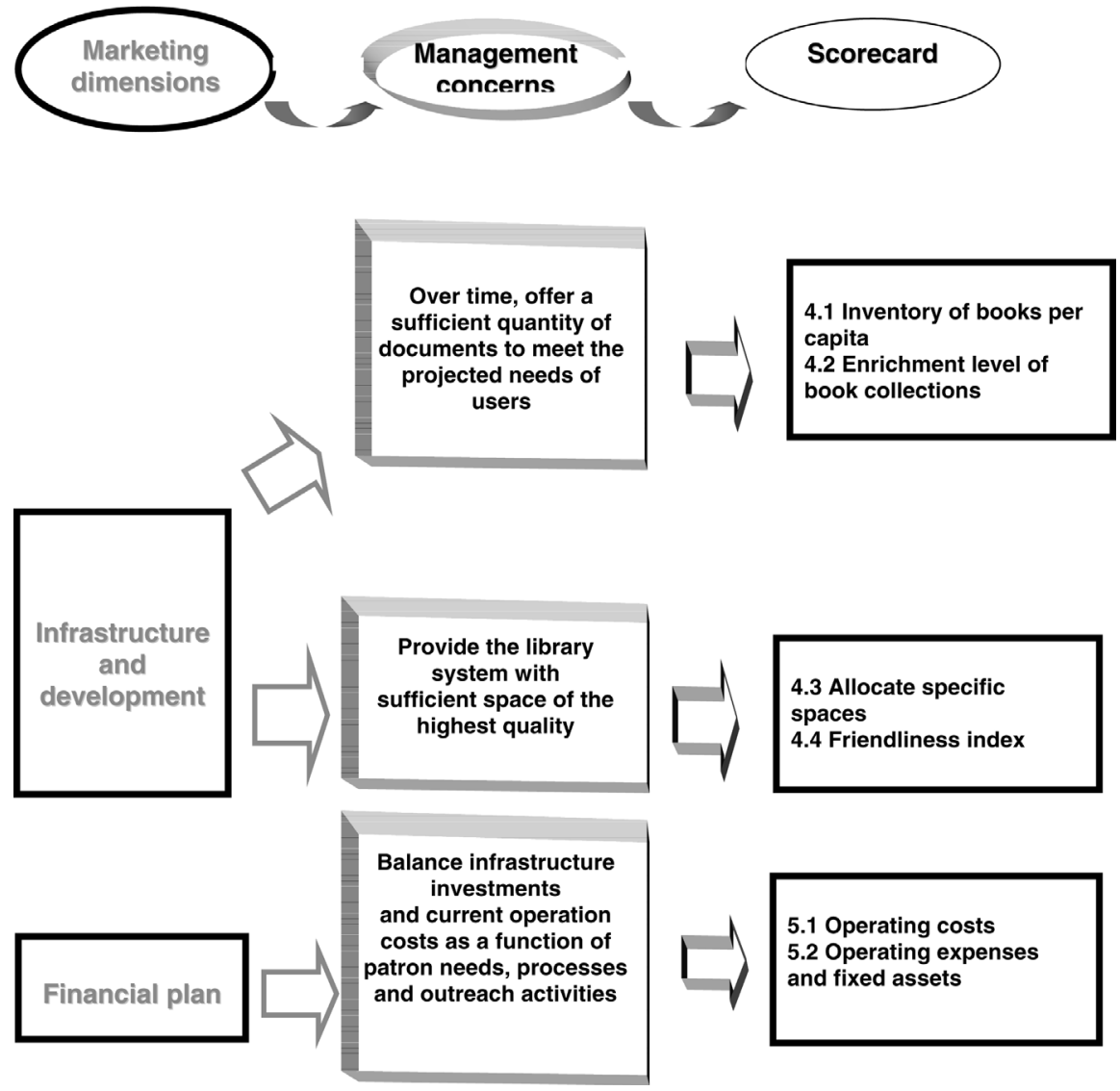

Figure 3c: Consolidation Plan and Balanced Scorecard

- Creative design facilitating the new library areas to create specific spaces for new knowledge development programs;

- Appropriate distribution of spaces to new interests and skills of specific clients as children, teenagers, baby boomer generation;

- Information broker, knowledge diffusing manager, electronic information editor as new role of public libraries;

- Development of new competencies and skills by new staffing models and specific professional development programs. 
The new Framework proposes a transverse approach in combining to these three strategic axes:

- Ensure Montreal's population has access to high-quality service

- Increase readership and library visits among people under 17 years of age

- Strengthen library use as a tool for integration and social development

Also, the settlement of the Framework is based on ten specific objectives or management concerns as illustrated and more than 40 minimal services or quality standards related to ten areas of standardization. These standards will support accurate strategies and selected initiatives according to the mission of a public library services in a $21^{\text {st }}$-century world.

On strategic level, according to the orientations of this framework, 31 core measures are selected and submitted to a Balanced-scorecard model as described in next section.

\section{PROPOSED BALANCED SCORECARD MODEL}

The selection of performance measures included in the Strategic Balanced Scorecard was determined and limited by 20 comparative graphic presentations of 31 measures and presented on one page (see appendix).

- CLIENTELE: 6 performance measures

- PROCESS: 10 performance measures

- OUTREACH AND DEVELOPMENT: 6 performance measures

- INFRASTRUCTURE AND DEVELOPMENT: 5 performance measures

- FINANCIAL PLAN: 4 performance measures

Six other performance measures are not included in the present graphics (PROCESS: 1; OUTREACH AND DEVELOPMENT: 1; INFRASTRUCTURE AND DEVELOPMENT: 2 and FINANCIAL PLAN: 2). The general model consists of estimating the performance indicator for each management concern, as a function of targets (expected outputs according to reasonable progressive timetable) or standards. Three Alert indicators will be determined: green signal light - achievable target; yellow signal light - challenge to face, and red signal light - reverse trend. They should help us to take a decision for more complete analysis or for immediate action to upgrade the investments or to adapt some initiatives.

Also it is important to mention, the expected outputs and targets mentioned in graphical figures of present Balanced Scorecard Model are not definitive and have to be considered temporary figures. These expected and updated outputs will be estimated and based later on results of benchmark studies with Canadian public li- 
braries serving 500,000 residents and more and on other recognized models of standardization.

\section{Multi-level Predictions model (library uses indicators)}

Effectively, the expected outputs and targets for library uses are based on the results of the application of a multi-level prediction model.

The hypothesis of the first level of comparative analysis is to staffi the service points of each borough of Montreal at the level of the equivalent mean per inhabitants level of human resources available per branch in 8 Canadian public libraries systems serving 500,000 residents. There is large probability that we can attain a comparable library uses ratio as circulation per capita. Some conditions will be required to optimize the distribution of staff in public services by reducing the human resources in multiple cataloguing and processing units, to develop new virtual and electronic reference services, to increase opening hours substantially and to initiate more outreach and without-walls mediation programs.

The second hypothesis of the benchmarking approach is to increase and upgrade holdings of the collection of books to 3 books per inhabitants, i.e. to the high-level of resources available in the same Canadian public library systems. There is large probability that we can offer a comparable quality of documentary services.

The second level of the prediction model is based on the high Pearson correlation factors of library uses indicators as circulation: number of physical entries (physical visits), active borrowers and reference questions answered with staffing and holding. Our correlation analysis is based on data for 44 service points during the period 2002-2006 for each month; it could be considered as a representative sample. The analysis has indicated the library uses as circulation is more affected by variation of human resources (Pearson correlation of 0.888 ) than holding of circulated documents (Pearson factor of 0.872) with high accurate rate. Regarding these high correlations, we proceeded to a regression analysis to determine the specific impacts of these two dependent variables.

Our model, based on the combined linear regression analysis of correlations with the progressive increasing of human and documentary resources to the targets of equivalent mean of resources attributed by 8 Canadian public libraries systems (benchmark sample), will determine the targets in terms of circulation and visits per inhabitants. Also, it is possible to estimate the potential market penetration rate and rotation or turn-over rate. These performance indicators and the level of standardizing process improving by this model are submitted to a balanced-scorecard report issued periodically. Our benchmarking includes an adjustment factor for the distribution of staff in cataloguing and processing unit and public services. The cataloguing and processing activities are more centralised in other large Canadian library services and we consider an adjustment factor. The cataloguing and processing activities in our library system will be centralised in short term at a level $80 / 20$ ( $80 \%$ centralised, $20 \%$ will be processed by boroughs). It is in part more decentralised than in other Canadian libraries but less than the present situation. 


\section{Clientele}

The first management concern, 'Increase number of visits and use of document services with special emphasis on young people' will be evaluated in terms of:

- Circulation per capita (loans per capita) - expected outputs according to benchmarking studies with the 8 largest Canadian public libraries serving 500,000 residents and more for 2009, 2011 and 2014

- Circulation per capita by segments (Monographs and multimedia) - same comparative timetable

- Visits per capita - same comparative timetable

- Penetration rate (market penetration rate) by age group - expected outputs according to benchmarking studies for 2011 and 2014

for the present year (2006), distance to previous year (2005) and \% of gap with next target year. (Figure 4)

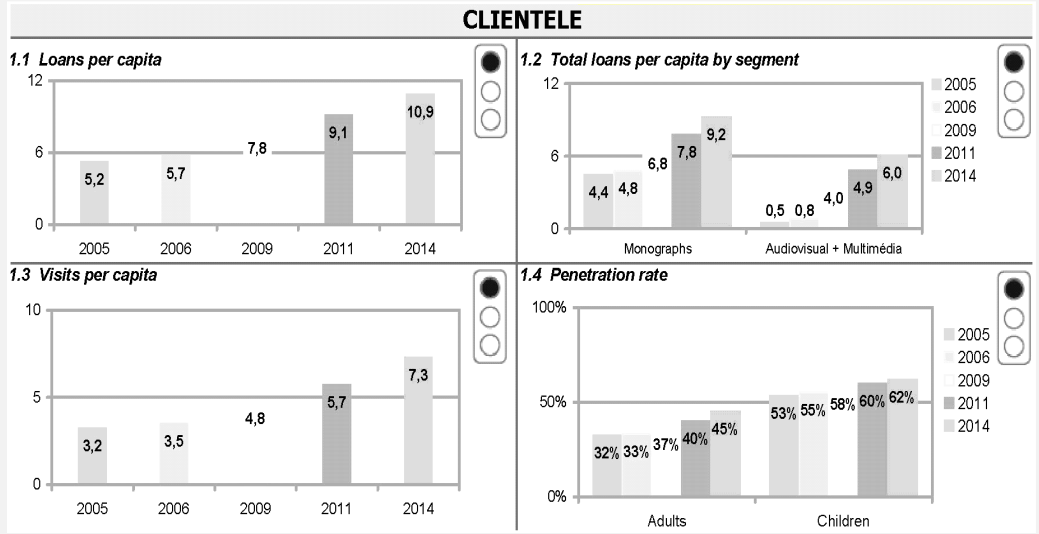

Figure 4: Clientele evaluation

\section{Process}

The second management concern, 'Expand services offerings in the areas of welcoming and helping patrons; reader advisory services; in-house and outside activities (mediation and outreach - without walls); reference and electronic reference; and documentary services for young people' will be evaluated in terms of:

- Ratio of professional and customer-services employees per capita - in comparison with standard for these areas 
- Number of reference questions answered / reference professionals as expected for 2009, 2011 and 2014, related to previous indicators of uses concerning the Clientele dimension as evaluated for the present year, distance to previous year and \% of gap with next target year

- Number of liaison agents per borough in comparison with standard provided for 2011 and 2014

The third management concern, on technical services units ('Ensure high-quality materials processing as quickly as possible as the lowest possible cost') will be evaluated in terms of:

- Unit cost of materials processing in comparison with cost of previous year and expected standard cost provided for 2009, 2011 and 2014

- Cost of item processing per hour or unit measure for time required to deliver

Finally, the fourth management concern, 'Optimize the activities of Central divisions with regard to the Consolidation Plan', will be evaluated in terms of:

- Number of employees in the Central divisions (systems, evaluation and planning and development of programs) in relation to the boroughs in comparison with the standard

- standard per capita portion of the budget set aside for the planning and development of new programs and services in comparison with required standard

These are illustrated graphically in Figure 5.

\section{Outreach and development}

The fifth management concern, relating to the marketing dimension 'Outreach and development: Establish outside programs to promote economic, social inclusion and cultural development' will be evaluated in terms of:

- Number of participants in organized and reader advisory activities per staff in comparison with expected participants per standard required staff

- Number of organized activities carried out / staff member dedicated to these activities in comparison to projected number of activities / per standard number of staff dedicated

- Level of loans per capita and penetration rate in target geographic area according to projected growth of level of loans per capita and penetration rate in comparison with previous year and present year

- Number of activities per week within the educational community and extramural activities

The next management concern, 'Ensure that libraries are closer to the population and that there is optimal territorial coverage' will be evaluated in terms of: 


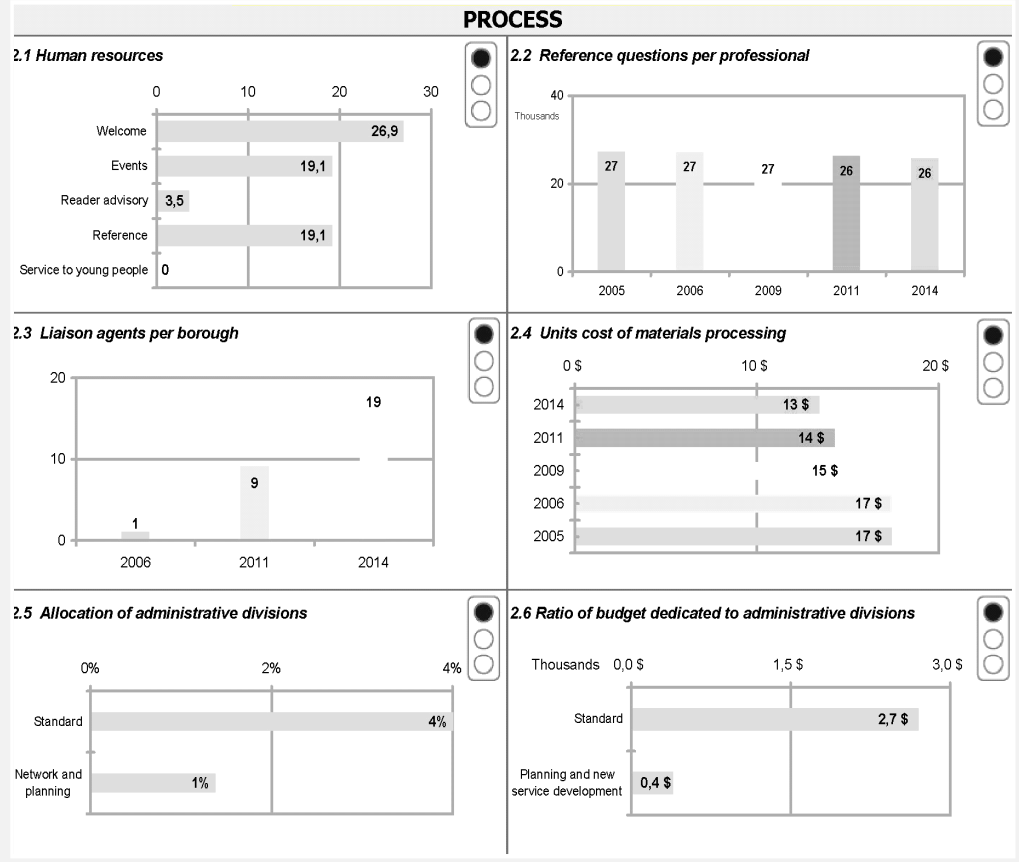

Figure 5: Process evaluation

- Composite index of territorial coverage (CITC), cumulative and standardized as a function of the variable radius of area covered (new developed model of standardized indicator as we will present later), population density, migration of users between boroughs, the distance between service points and other factors in comparison with projected CITC standard indicator

and the seventh management concern, 'Gradually free up extra budget to promote the initiatives and service offerings of libraries among the residents of Montreal' will be evaluated in terms of:

- Portion of Budget dedicated to promotion / overall operating Budget and by borough

- Portion of Promotion Budget dedicated to initiatives / overall promotion budget and by borough

- in comparison with actual and projected target year

These are illustrated graphically in Figure 6. 


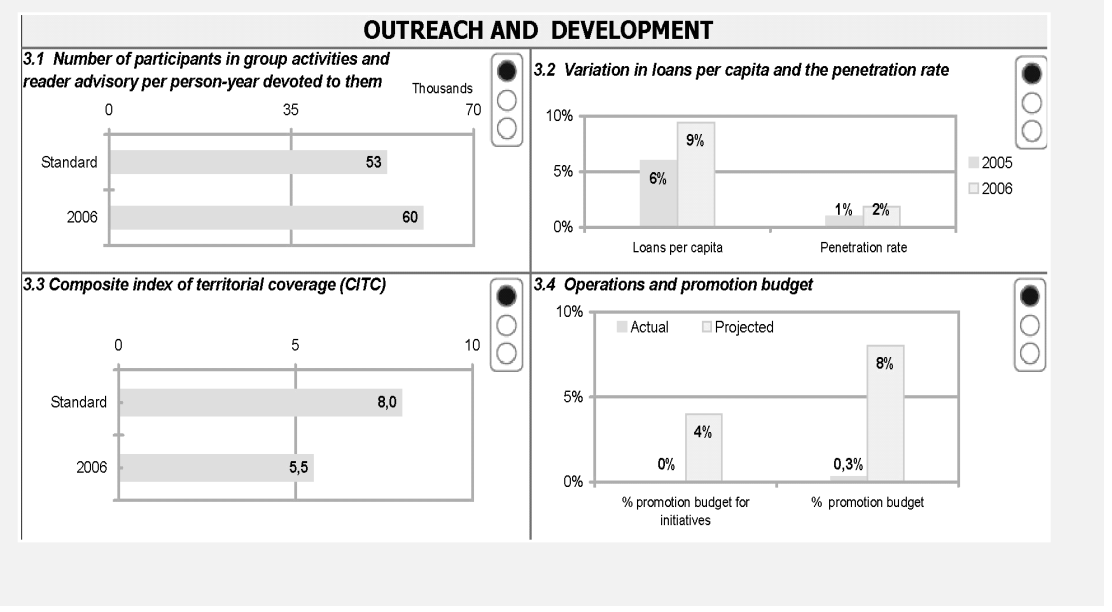

Figure 6: Outreach and development evaluation

\section{Infrastructure and development}

The first management concern (number 8) in regard with infrastructures 'Over time, offer a sufficient quantity of documents to meet the projected needs of users' will be evaluated in terms of:

- Number of books per capita on an overall basis and by borough in comparison with projected minimum standard of 3.0 books per capita to be progressively attained from present year (2006) until 2014

- Quantities of other forms of library materials on an overall basis and by borough in comparison with standard projected quantities required of other forms of library materials to be detailed

- Inventory (holding) by materials segments, on an overall basis and by borough, as a function of the Consolidation Plan

- Book collections enrichment rate in respect with the inventory (holding), on an overall basis and by borough, in comparison with standardized book collections enrichment rate in respect with the standard inventory

- Rotation rate (or turnover rate) of the general circulated monograph collection and specific collections, on an overall basis and by borough, in comparison with standardized projected rotation rate of the general circulated monograph collection and specific collections estimated according to expected outputs related to the Clientele dimension.

The management concern number 9, 'Provide the library system with sufficient space of the highest quality' will be evaluated in terms of: 
- Deficit in required space per 1,000 residents per borough in comparison with projected standard equivalent to $57,5 \mathrm{~m}^{2} / 1,000$ residents per borough, related to mean space per 1,000 residents of 8 large Canadian public libraries serving 500,000 residents and more

- Space planned for organized activities (animation and mediation - outreach) and reference from present year until 2014, graphical presentation non presented

- Friendliness index (to be defined) in terms of number of libraries and service points, on an overall basis and by borough in comparison with standard projected friendliness index to be attained from present year until 2014.

These are illustrated graphically in Figure 7.

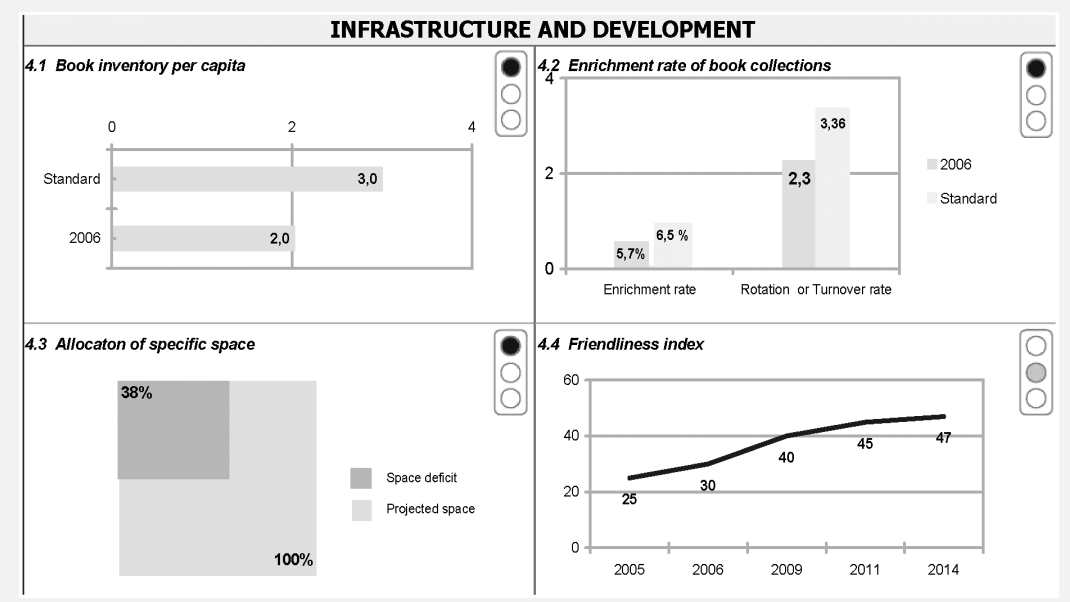

Figure 7: Infrastructure and development evaluation

\section{Financial plan}

The last management concern (number 10), 'Balance infrastructure investments and current operating costs as a function of patron needs, processes and outreach activities according to the Consolidation Plan timetable' will be evaluated in terms of:

- Costs per number of loans in comparison with projected costs in function to expected loans

- Costs per number of visits in comparison with projected costs in function to expected visits

- Costs per number of residents in comparison with projected costs 
If the deviation is negative, it must not surpass $5 \%$ of the borough trend.

- Additional operating expenses for the overall Consolidation Plan and by borough in comparison with expected additional operating costs in function with provided timetable. Not included in present graphics

- Growth rate of the extra investments and operating budgets according to the schedule for target years 2009, 2011 and 2014

- Assets anticipated for the overall three-year assets plan and the plan for each borough in comparison with fixed assets. Not included in present graphics

These are illustrated graphically in Figure 8.

In the proposed Balanced Scorecard, related measures such as 'Loans per capita', 'Percentage of the target population reached' and 'Collection turnover' are well identified by appropriate graphic analysis for both categories of the Balanced Scorecard. It cannot replace any analysis but it will alert us to potential sources of problems. Also, the impacts of financial support and promotion on output performance measures are integrated into the Balanced Scorecard Model. So, the liaison between management concerns associated to distinctive dimensions is takien into consideration by our Balanced Scorecard Model.

For example, if Collections rotation rate is very high and Loans per capita is low or decreasing, we have to consider the results of related measures; and if the investments are relatively high or in increasing trend, we have to proceed to some other analysis to determine the sources of problems, as the relevance or consistency of some initiatives.

FINANCIAL PLAN

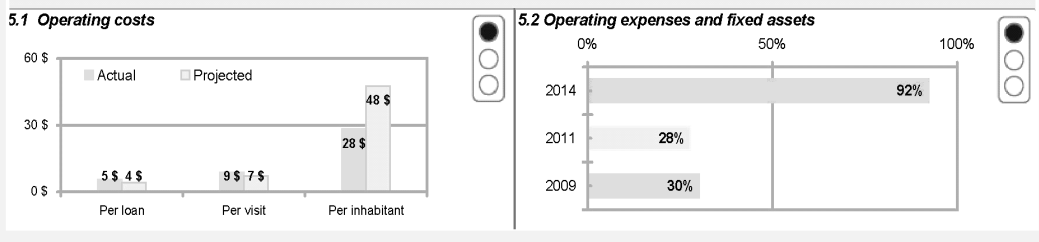

Figure 8: Financial plan evaluation

These initiatives are a means of achieving operational objectives and the targets that define them. Here is a selection of targets:

- Develop the knowledge portal

- Introduce new cultural products

- Develop activities that are strong attractions, in harmony with the values of identified groups

- Adapt the collections in light of the outreach activities to be developed

- Diversify the human resources in libraries 

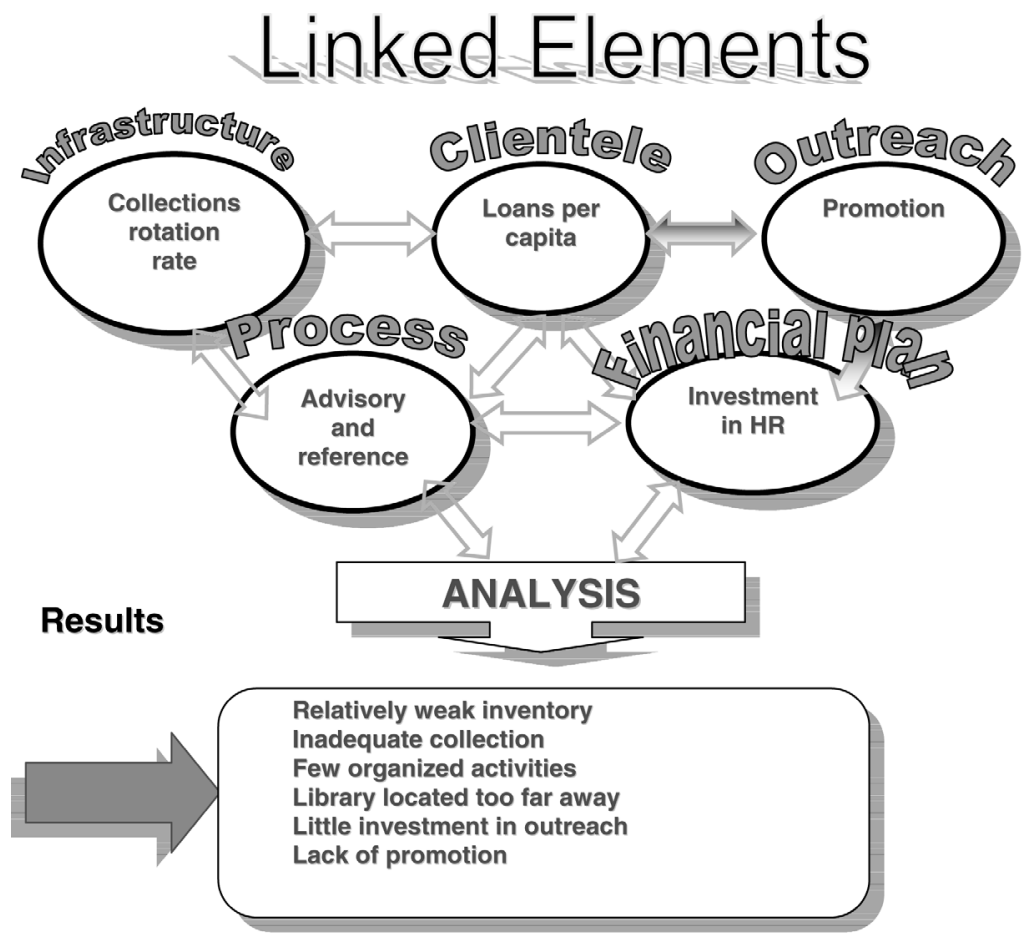

Figure 9: Linked elements

\section{HIERARCHICAL LEVELS OF THE SCORECARD (CASCADE)}

By the same transverse approach, we proceeded to the 'cascading' process of developing Balanced Scorecards in relation to the decentralised unit services, the branches or service points administrated by boroughs.

It is very important to consider the performance measures identified in Strategic Balanced Scorecard as attributed to the results of local uses, resources invested by boroughs and general trends of boroughs.

While some of the objectives and measures used may be the same throughout the entire organization, in most cases lower-level Scorecards include items reflecting the specific opportunities and challenges faced at those levels.

But, considering the important decentralization of Montreal Public library System on responsibilities level, and to provide a form of imputability of boroughs to the Consolidation Plan settlement process based on progressive attainment of minimal standards (with performance), it is imperative that the indicators in the Operational Balanced Scorecard model are determined and related to key objectives and measures of success provided by the highest-level (Strategic) Balanced Scorecard. 
Some more detailed measures and trend comparisons of boroughs and service points predetermined by comparisons criteria will insert some relevant ranking tables to facilitate the analysis and evaluation (justification) of the performance of service points in some areas for local managers.

Concerning the Tactical level, some measures to facilitate the evaluation of results or the limits of the capacity of the organization - as for example loans per employees - are included in Operational Balanced Scorecard. Others more strategic measures were associated and included in the Strategic Scorecard. We avoid creating a third and distinctive category of Balanced Scorecard.

In accordance with the Strategic Balanced Scorecard we illustrate a proposed parallel Operational Balanced Scorecard for the first marketing dimension Clientele. We present only the first dimension but a cascading process was conducted for the five dimensions. The model will be submitted to Committee of Minimal standards and to boroughs during the coming months.

\begin{tabular}{|c|c|}
\hline \multicolumn{2}{|c|}{ Illustration of the Cascade Effect of Hierarchical Levels on a Scorecard } \\
\hline Strategic & Operational \\
\hline $\begin{array}{l}1.1 \text { Sum of document loans and downloaded } \\
\text { items }\end{array}$ & $\begin{array}{l}\text { 1.1 Sum of document loans and } \\
\text { downloaded items } \\
\text { Distribution of borough libraries } \\
\text { Growth of equivalent libraries } \\
\text { Distribution of loans per capita among young } \\
\text { people } \\
\text { Rate of loans per borrower (active) }\end{array}$ \\
\hline 1.2 Sum of loans per capita by segment & $\begin{array}{l}\text { 1.2 Sum of all loans per capita by segment } \\
\text { Distribution of borough libraries }\end{array}$ \\
\hline 1.3 Visits per capita & $\begin{array}{l}1.3 \text { Visits per capita } \\
\text { Distribution of borough libraries } \\
\text { Growth of equivalent libraries }\end{array}$ \\
\hline 1.4 Overall penetration rate and by age group & $\begin{array}{l}1.4 \text { Overall penetration rate and by age group } \\
\text { Penetration rate by borough and age group }\end{array}$ \\
\hline & $\begin{array}{l}\text { 1.5 Number of opening hours } \\
\text { - Distribution of borough libraries } \\
\text { - Change in outside loans } \\
\text { - Change in total outside loans } \\
\text { - Relative share of additional loans } \\
\text { - Change in number of new members } \\
\text { - Change in number of visits } \\
\text { - Average hourly loans } \\
\text { 1.6 Number of active borrowers } \\
\text { - Distribution of borough libraries } \\
\text { 1.7 Percentage satisfaction rate } \\
\text { 1.8 Number of times documents are consulted } \\
\text { on-site }\end{array}$ \\
\hline
\end{tabular}


We expected some measures will be useful tools for managers to have a better follow-up of impacts of some investments as for the increase of opening hours. They could be related to results detected by Strategic Balanced Scorecard but not directly.

Some other measures could justify with more details the level of results for the overall basis as defined in Strategic Balanced Scorecard as a percentage of satisfaction.

Finally, by predetermined comparisons by boroughs or equivalent service points (as ranking tables), these measures will alert local managers to some problems, weaknesses or trends and force them to be imputable to the Centralised Direction of Montreal Public Libraries System and support the consolidation settlement process. Also, considering large disparities for some boroughs, these more specific measures will be imperative for us to understand some results.

In conclusion, with the Operational Balanced Scorecard, more detailed measures were determined in order to facilitate the comparison of branches and boroughs, to equivalent units or to tendencies by following the Public Libraries System. These last measures will be associated to the operational level and will have an impact on the responsibilities of borough's library services managers regarding progress toward the provided target outputs. The timetable was determined for some target outputs. Finally, the evaluation of the contributions of branches and boroughs, by specific investments and initiatives to strategies related to the Consolidation Plan will be represented by the Operational Balanced Scorecard. The output measures will be submitted to comparative analysis with specific socioeconomic factors and will be improved by the outcomes evaluation process of all service points.

As explained in the previous presentation of the Operational Balanced Scorecard, we provide predetermined ranking tables to facilitate comparisons of trends followed by some boroughs or by equivalent service points located in independent boroughs. This cascading approach will create another linkage with performance indicators of the Strategic Balanced Scorecard. These detailed measures were determined in order to facilitate the comparison of branches and boroughs, to equivalent units or to tendencies by following the Public Libraries System. Also, these measures will be associated to the operational level and will have an impact on the responsibilities of borough's library services managers regarding progress toward the provided target outputs. The timetable was determined for some target outputs.

Finally, the drilling process into the operational Scorecard offer another option to qualify the trends followed by comparable service points or by boroughs in comparison with the overall Library System. In this way we determine some specific targets and quality criteria but essential and related to strategic objectives for Consolidation Plan settlement. For example, see the present Core sample:

- Position of boroughs concerning loans per capita - maximum deviation of $5 \%$; 


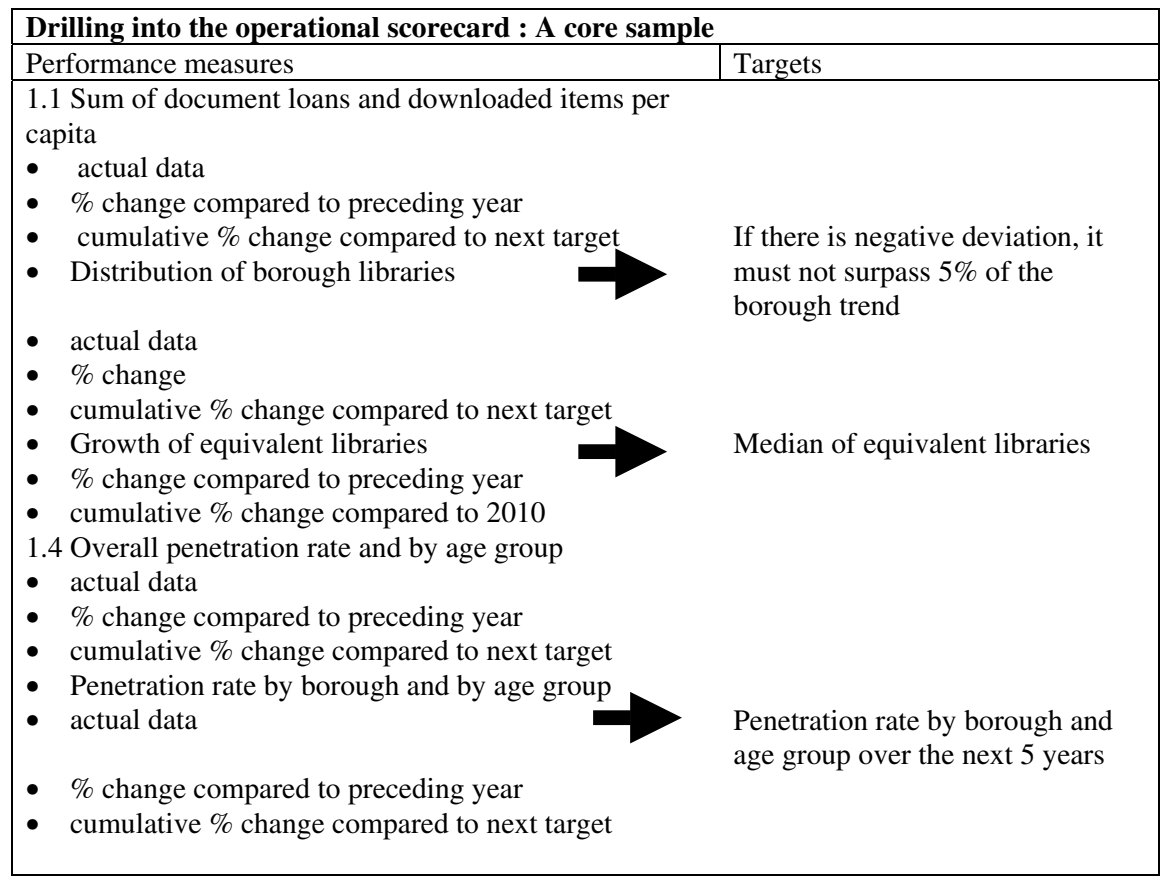

- Growth of equivalent service points in term of circulation relatively to next target - Median of equivalent libraries;

- Penetration rate by borough and by age group - Penetration rate by borough and by age group over the next 5 years.

By the way, the cascading process and drilling options with inserted comparisons of boroughs or equivalent service points will create a better linkage between Strategic (highest) Balanced Scorecard with Operational Balanced Scorecard and facilitate the achievement of standards and targets of the Consolidation Plan.

Also, our Balanced Scorecard model will be an excellent tool for monitoring of laggards and vulnerable boroughs with lack of resources or low performance with socio-demographic factors extremely strategic in regard to the Consolidation Plan. (Figure 10)

As mentioned previously, we anticipate inserting for some targets of the Operational Balanced Scorecard comparisons of deviation to some average or median performance measures estimated for families of equivalent libraries or boroughs according to relevant criteria for management concerns and marketing dimensions. These equivalence criteria could be of the order of common demographic, economic or social characteristics of the population served in the concerned area or of the equivalent rate of uses (loans) or size of resources (human resources or documentation) or types of clientele or services provided (as for ethnic populations, 
teens, young people with problems of school dropout). (See table 'Families of Equivalent Libraries')

\begin{tabular}{|c|c|}
\hline \multicolumn{2}{|c|}{ Families of equivalent Libraries } \\
\hline $\begin{array}{l}\text { Snapshot } \\
\text { - demographic } \\
\text { - economic } \\
\text { - } \quad \text { social }\end{array}$ & $\begin{array}{l}\text { Equivalence criteria } \\
\text { - Geographic location } \\
\text { - } \text { Average household income } \\
\text { - Unemployment rate } \\
\text { - Proportion of single-parent families } \\
\text { - Proportion of immigrants in the population } \\
\text { - } \text { Proportion of } 15 \text { to } 24 \text { year olds who do not attend school } \\
\text { - Adults without high school graduation }\end{array}$ \\
\hline Library use & $\begin{array}{l}\text { Loans } \\
\text { Human resources and documentation } \\
\text { Services provided } \\
\text { Types of clientele }\end{array}$ \\
\hline
\end{tabular}

\section{Borough Evaluation Measures}

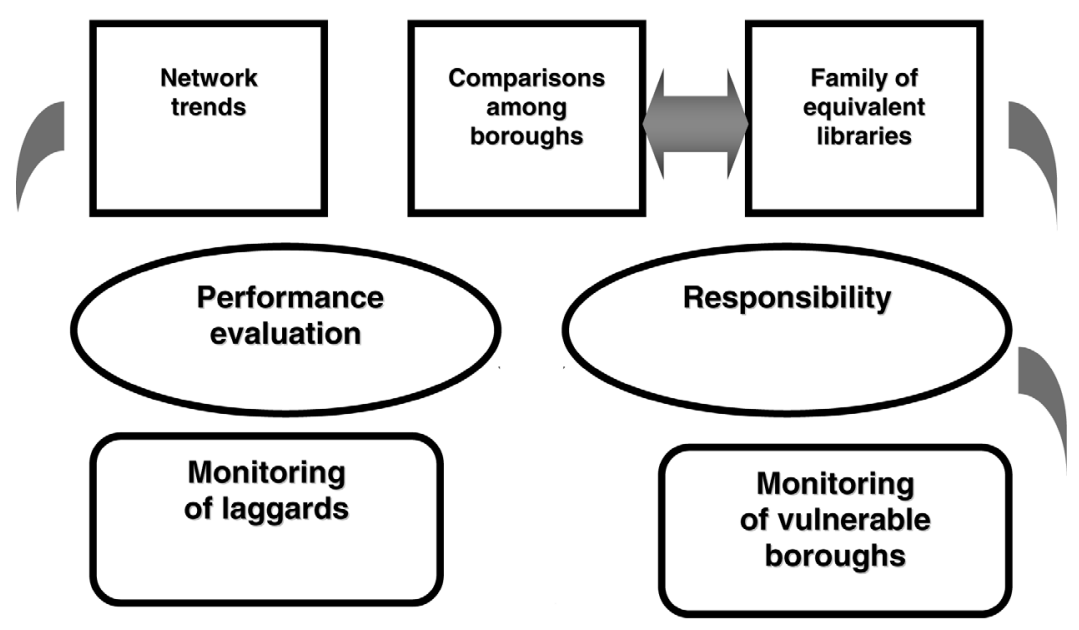

Achieve standards and targets of the Consolidation Plan

\section{Operational Scorecard}

Figure 10: Borough evaluation measures 


\section{STANDARDS ADAPTED TO DISPARITIES AMONG MONTREAL'S BOROUGHS}

For Montreal, it is imperative to provide measures to allow comparison of branches and boroughs as some results of the Assessment indicate to us large disparities among boroughs on demographic and economic factors of the population; and for other factors as school levels, we could find opposite trends. (Figure 11)

But the same boroughs present important lack of human and documentary resources in comparison with Canadian public libraries serving 500,000 residents and more. Approximatively, less than $12 \%$ of Montrealers could use equivalent of $80 \%$ of resources offered by large Canadian Public libraries, in terms of collections, professional support by sufficient qualified staff and space.

The Balanced Scorecard Model as presented was proposed before the completion of all simulations and benchmark studies required to determine quality standards. This approach will permit the focus to be on the main minimal service standards and performance measures required to produce the Consolidation Plan. The interdependence of some performance measures for processes and scope of services with target outputs related to clientele will facilitate the determination of optimal resource uses, including collection turnover. In consideration with disparities of boroughs, decentralized responsibility in regard with libraries and strategic axes of Consolidation Plan, we addressed these areas of standardization.

\section{DISPARITIES AMONG BOROUGHS}

\begin{tabular}{|c|c|c|}
\hline Population & $\sum$ & 17.700 to 163.100 \\
\hline I mmigrants & $\sum$ & $12.1 \%$ to $48.5 \%$ \\
\hline Average household income & $\sum$ & $\$ 34.200$ to $\$ 142.600$ \\
\hline $\begin{array}{l}\text { Population with university- } \\
\text { level studies }\end{array}$ & $\sum$ & $11.6 \%$ to $68.2 \%$ \\
\hline $\begin{array}{l}\text { Population with } \\
\text { secondary } V \text { certificate }\end{array}$ & $\sum$ & $4.7 \%$ to $17.7 \%$ \\
\hline Young people in the population & $\sum$ & $7.7 \%$ to $23.6 \%$ \\
\hline
\end{tabular}

Figure 11a: Disparities among Boroughs: Overview 


\section{DISPARITIES AMONG BOROUGHS HUMAN RESOURCES}

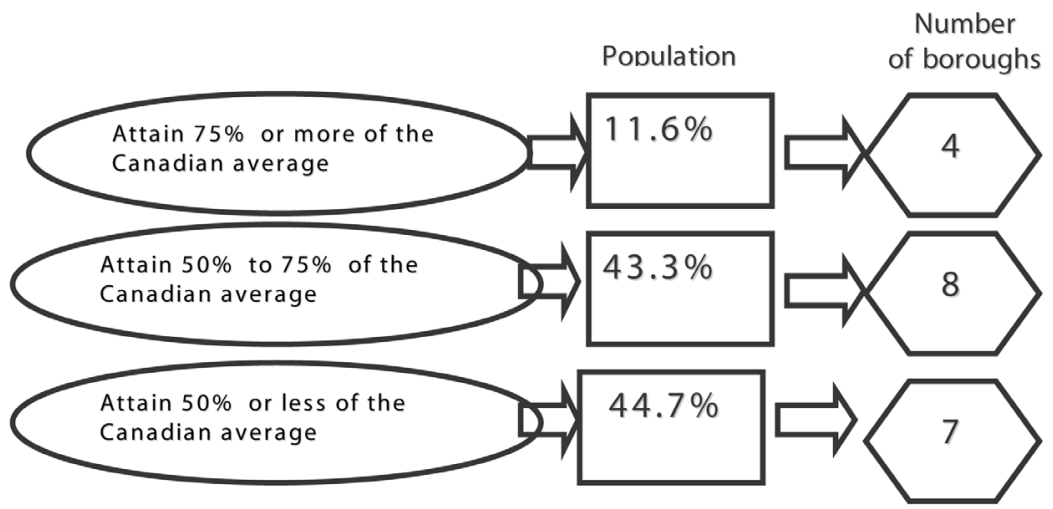

15 of 19 boroughs do not attain $75 \%$ of the Canadian average for cities with $500,000+$ residents, that is $88 \%$ of the population.

Standard:

0.86 librarians $/ 6,000$ residents

1.43 employees/2,000 residents

Figure 11b: Disparities among Boroughs: Human Resources

\section{DISPARITIES AMONG BOROUGHS}

\section{SPACE}

Population

Number of boroughs

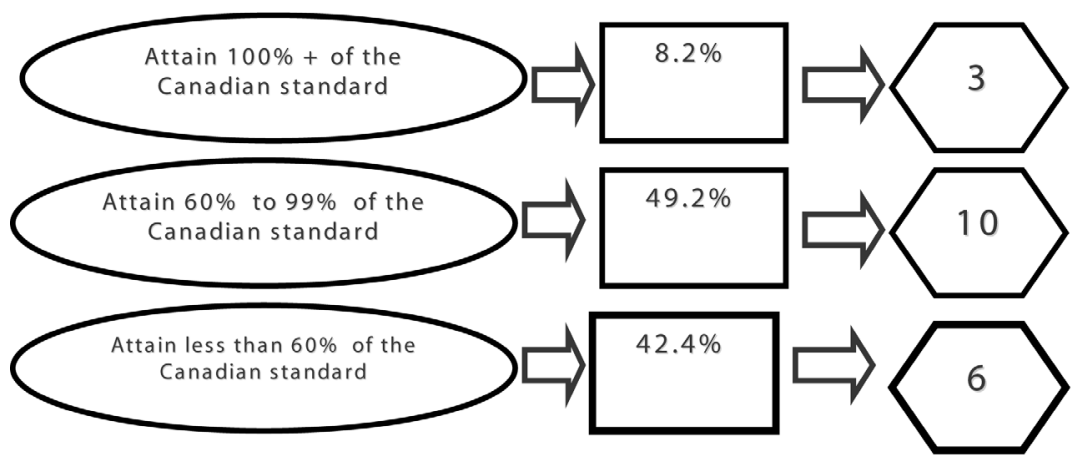

16 of 19 boroughs do not attain the Canadian average for cities with $500,000+$ residents, that is $91.7 \%$ of the population. 


\section{DISPARITIES AMONG BOROUGHS BOOK COLLECTIONS}

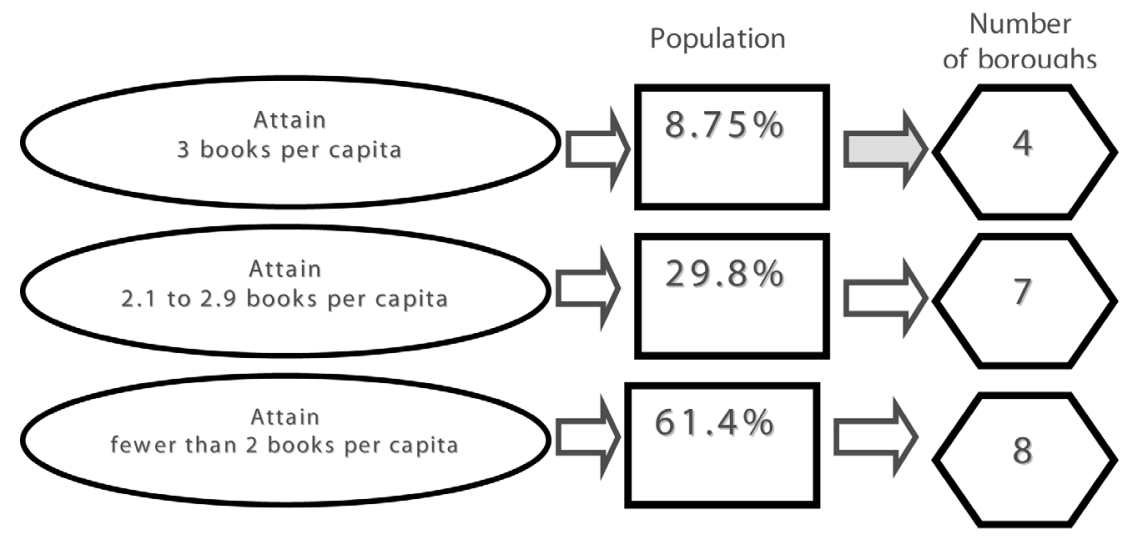

15 of 19 boroughs do not attain the target of 3 books per capita, that is $91.2 \%$ of the population.

Standard: 3 books per capita

Figure 11d: Disparities among Boroughs: Book Collections

Some additional new minimal standards, proposed to support the Integrated Consolidation Planning Process at the Montréal Public Libraries System, were proposed as more appropriate quality parameters and performance measures for a large and urban public library system, including variable radius of space services and combined indicator of non-duplicated opening hours with aggregated opening hours per serving population:

- 10 Areas of Standardization

o Minimum space standard

o Criteria for location of service points and sub-branches

o Minimum opening hours

o Reduced deficit for building maintenance

o Universal loans and returns for the entire network

o Unified management information system for documents

o Access to library collections

o Axes for collections development along language lines

o Provision of human resources as a function of service levels, hours of opening, population to be served and reader advisory needs

o Services aimed at specific categories of users 
- Montréal Standards Being Applied per Borough

o Service areas with variable radius $(0.75$ to $2.4 \mathrm{~km})$

- migration of patrons

- population density in an urban environment

o Opening hours

- not double counted (62 hours) - non-duplicated opening hours

- per 1,000 residents (92 hours) - aggregate opening hours

- $50 \%$ of hours (not double counted) outside of business hours

- 324 days, not double counted - non duplicated opening days

o Space: $57.5 \mathrm{~m} 2 / 1,000$ residents

o Staffing

- 0.86 librarians $/ 6,000$ residents

- 1.43 employees/2,000 residents

Besides, the Montreal territory is characterized by a marked variety in concentrations of population. For example, 50\% of Montrealers live in just 7 boroughs. These 7 boroughs cover 33\% of territory superficies on Montreal Island. According to Standards of Quebec, the population to be served should be localized inside of a radius of service equivalent to $1.5 \mathrm{~km}$. (Figure 12)

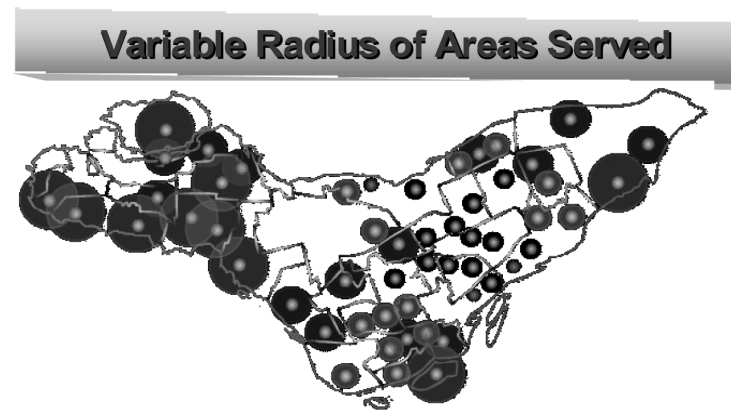

\section{MONTRÉAL}

Population density:

$0.75 \mathrm{~km}$

Area served

major variation, which has

an impact on areas served

$1.00 \mathrm{~km}$

D Densely populated

6,164 to $11,274 / \mathrm{km}^{2}$

- Density varies, depending on the borough, from 650 to more than 13,000 residents per $\mathrm{km}^{2}$.

- $\mathbf{5 0} \%$ of the population is concentrated in 7 boroughs.

- These 7 boroughs occupy $33 \%$ of the territory.

$1.50 \mathrm{~km}$ Sparsely populated 2,122 to $3,998 / \mathrm{km}^{2}$ Very sparsely populater 348 to $2,121 / \mathrm{km}^{2}$

(Québec standard: 1.50 km) 
By this traditional approach with fixed dimension of radius of service, the concentration and overlap of radius of service, localized specifically in the center of the Island of Montreal, could be considered as overestimating service in relation to real needs. Some simulations were analysed to identify the real deficit of service points or library services on the territory.

The simulation of radius of service equivalent to $0.75 \mathrm{~km}$ for libraries localized in borough with a very large density of population should be probably more appropriate, illustrating the deficit in service points. Also, for boroughs with less density of population, the size of radius of service could be increased more than $1.5 \mathrm{~km}$ as recommended by Standards of Quebec as 2.0 or 2.4 for boroughs with weak density of population. This analysis will facilitate the determination of a basis for criteria of application of minimum standards as a function of proximity indicator, density of population, distance between neighbour libraries and sociodemographic characteristics of boroughs.

This approach is used to optimise the reduction of disparities in terms of population served. The new criteria of application of minimum standards based on density of population and other socio-demographic factors instead of served population is more appropriate and relevant with regard to a urbanized territory such as Montreal and opens new perspective levels of services and inter-boroughs cooperation.

This is one of the original and innovative standards used for planning spaces according to the Consolidation Plan and will be used to propose a new target concerning Territory coverage index as to be inserted in Strategic Balanced Scorecard.

\section{MONTRÉAL STANDARDS BEING DEVELOPED}

- Human resources

o Welcome

o Reference

o Readers advisory

o Services for young people

o Cultural communities

o Outreach

- Service points

- Dilapidated buildings

- Friendly spaces

- Territorial coverage index

- Document resources

o Optimal rotation rates (as a function of outputs)

o Collections expansion index

o Document categories

o Enrichment rate 
Some original performance measures and standards will be inserted in the Balanced Scorecard Model, including the Territorial Covering Indicator (depending on multiple dimensions, including population density, socio-demographic factors, distance between service points, and variable area radius model), and the Combined Performance measure on quality and user-friendliness of space areas will be developed.

\section{CONCLUSION: NEXT STEPS ...}

In our next steps, according to the accurate strategies of the Framework, we will propose in September targets for the Clientele dimension according to results of benchmarking studies.

Also, standards concerning staffing and space area will be simulated with large Canadian public libraries and will be compared with other recognized models and practices in other parts of the world. This important step will permit us to simulate appropriate levels of services for boroughs of Montreal and to propose a multilevel standardization plan.

When these results are examined and validated by the Committee of minimal standards, the standardization process as described will be completed before the end of next year. This process will include a definition of strategies and concepts of focused functionalities such as welcome services, mobile libraries, service points, reference levels, outreach programs according to strategic axes of the Consolidation Plan.

A specific Consolidation Plan for library services to ethnic populations, with a more integrated approach, including new standards, will be completed in parallel.

Finally, we will begin in Fall 2008 and complete in 2009 the required works to reorganize the management information. Also, we will introduce progressively new integrated strategic and operational systems (included data warehouse management system), essential tools to realize appropriate and relevant management information system for a library network of the size of Montreal public libraries system.

\section{REFERENCES}

ANSI/NISO Z39.7-1995. The Library Statistics Standard. http://www.niso.org

Carbone, Pierre. 2002. Construire des indicateurs et tableaux de bord. Paris: Tec et Doc, 2002, 256 pp. (Coll. Boîte à outils).

Coates, Tim. 2004. Who's in charge? Responsibility for the Public Library Service. Libri - Laser Foundation, 2004, 29 p.

England. Department for Culture, Media and Sport, Libraries. Information and Archives Division. 2001. Comprehensive, Efficient and Modern Public Libraries: Standards and Assessment. [2001], 17 p. http://www.culture.gov.uk/PDF/ libraries_pls_assess.pdf 
Framework for the Future: Libraries, Learning and Information in the Next Decade. London: Department for Culture, Media and Sport, 2003. 59 p.

Giappiconi, Thierry. 2001. Manuel théorique et pratique d'évaluation des bibliothèques et centres documentaires. Paris: Electre-Éditions du Cercle de la Librairie, 2001, 223 p. (Bibliothèques).

Guillemette-Labory Louise and Meunier Pierre. 2006. «Quality Standards : Public libraries on the island of Montreal » in Management, Marketing and Promotion of Library Services Based on Statistics, Analysis and evaluation. [World library and information congress: Satellite meeting or Pre-conference of 71st IFLA General Conference and Council, August 9-11, 2005, Bergen, Norway]. Trine Kolderup-Flatten, ed. [International Federation of Library Association and Institutions]. München: K.G. Saur, 2006. pp. 80-106. (IFLA Publication: 120/121)

International Standards Organization. Technical Committee ISO/TC 46. Subcommittee SC 8. 2005. International statistics for libraries. Revision of 3rd ed. Geneva: ISO, 2005, v, 61 pp. (International Standard: ISO 2789).

International Standards Organization, Technical Committee ISO/TC 46. Subcommittee SC 8. 2006. Library performance indicators. Revision of 1st ed. Geneva: ISO, 2006, iii, 80 p. (International standard: ISO/DIS 11620).

Meunier, Pierre. 2004. Development of Québec public libraries: Profile of the standardization process at Montreal Public libraries System. World library and information congress: 70th IFLA General Conference and Council, August 2227, 2004, Buenos Aires, Argentina. http://www.ifla.org/IV/ifla70/papers/189eMeunier.pdf.

Meunier, Pierre. 2007. Proposed Prospective Balanced-Scorecard Model for the Montréal Public Libraries System. Submitted to the 7th Northumbria Conference [World library and information congress: Satellite meeting or Pre-conference of 73rd IFLA General Conference and Council, August 13-16, 2007, Cape Town, South Africa]. Proceedings to be published.

Niven, Paul R. 2006. Balanced Scorecard steb-by-step : Maximising Performance and Maintaining Results. $2^{\text {nd }}$ ed. Hoboken, N.J.: John Wiley and Sons, 2006. $318 \mathrm{p}$.

Pour des bibliothèques québécoises de qualité: guide à l'usage des bibliothèques publiques. Montréal: ASTED with Les Bibliothèques Publiques du Québec and Le Regroupement des CRSBP du Québec. 1996. 104 p.

Ville de Montréal, Service du développement culturel, de la qualité du milieu de vie et de la diversité ethnoculturelle, Direction du développement culturel et des bibliothèques, Division de la Planification et du développement du réseau des bibliothèques. 2005. Assessment of the Municipal Libraries on the Island of Montreal, translation of Diagnostic des bibliothèques municipales de l'île de Montréal. Montréal : July 2005, 87 p. Also up-dated figures and report for 2004. http://www2.ville.montreal.qc.ca/biblio/diagnostic/index.htm . 


\section{APPENDIX: PROPOSED BALANCED SCORECARD - SELECTION OF INDICATORS}

\section{Montréal 2005 Strategic Scorecard}

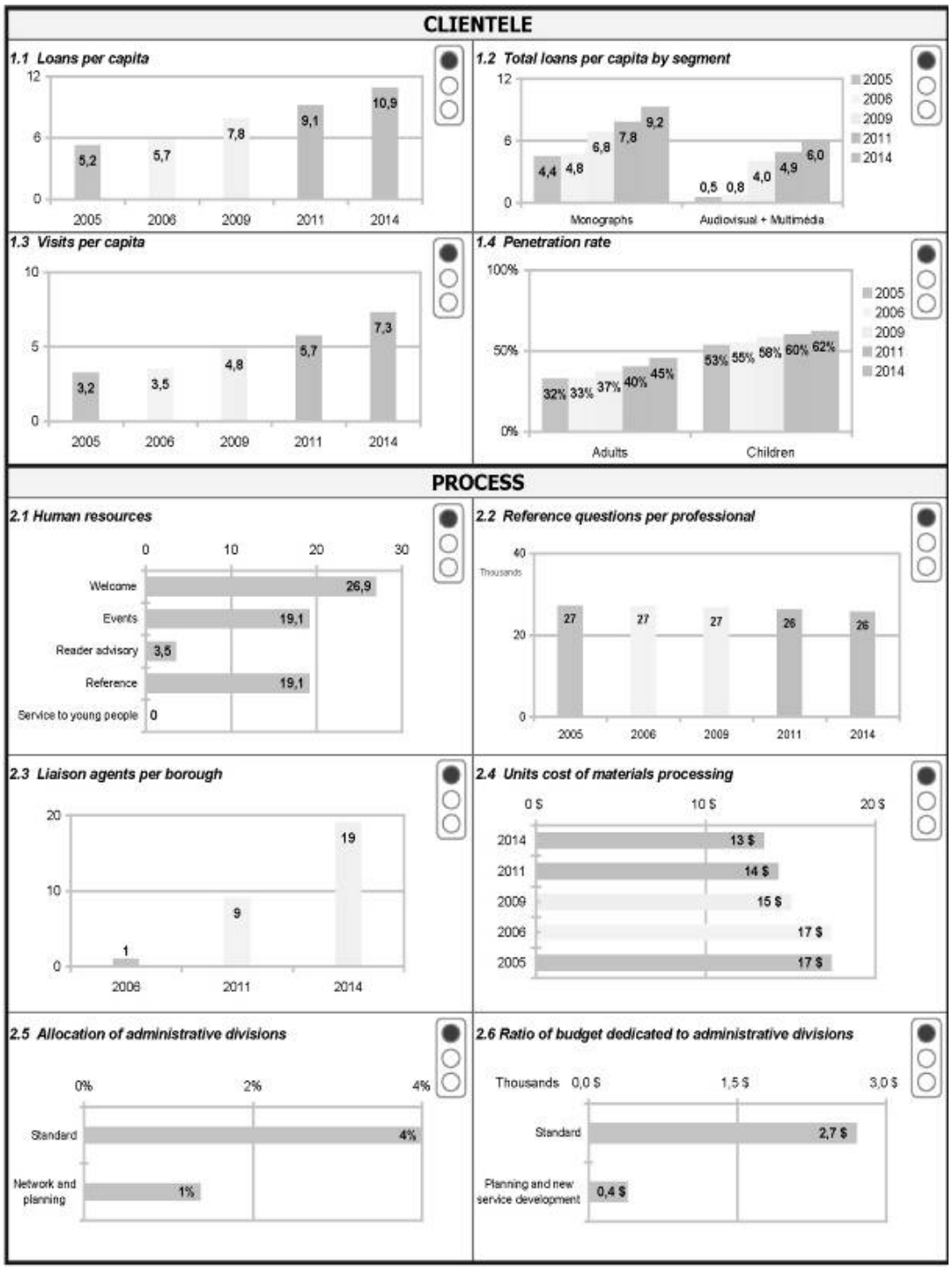




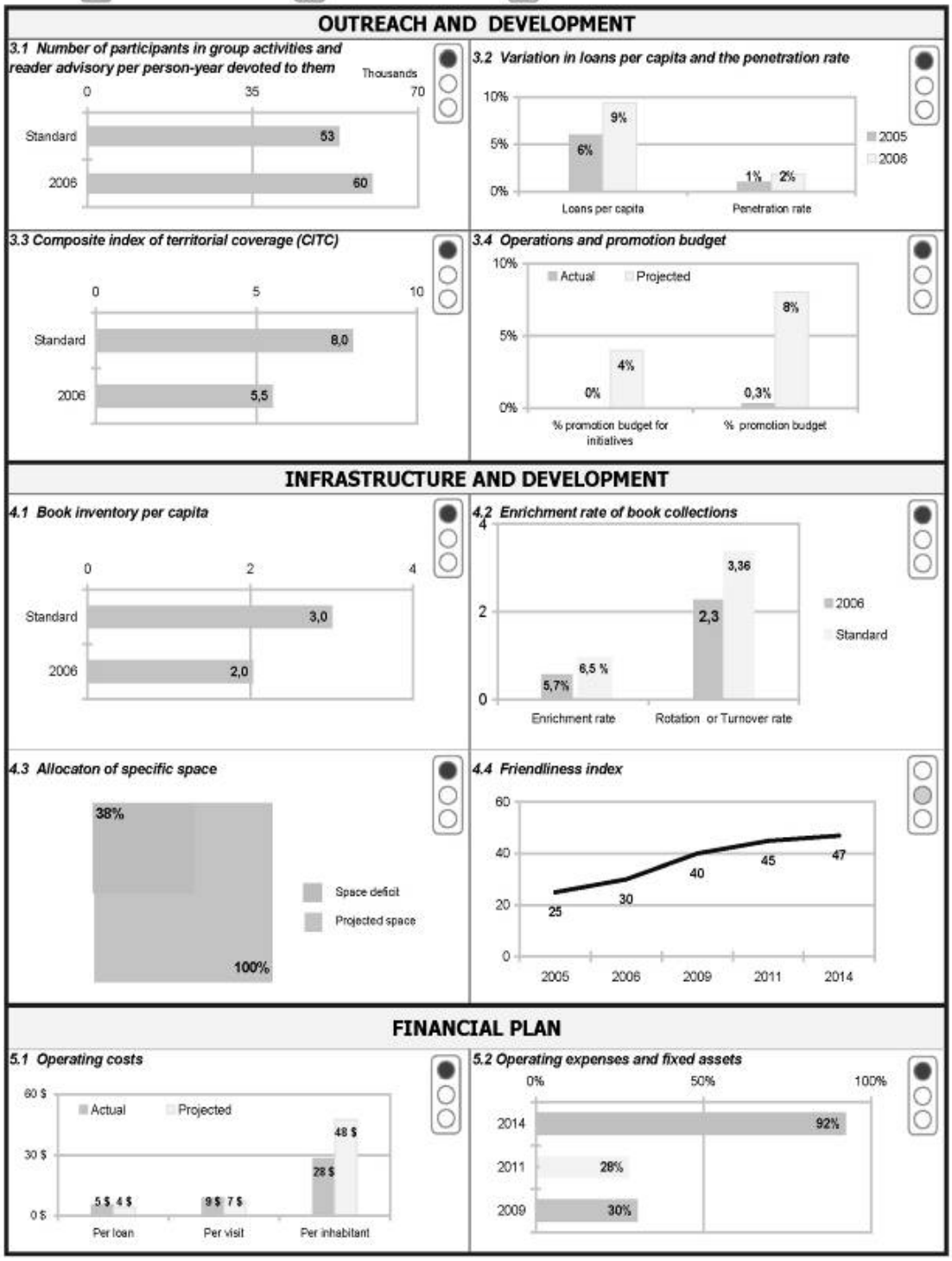

